\title{
Branding, Ingredients and Nutrition Information: Consumer Liking of a Healthier Snack
}

\author{
Mary R. Yan ${ }^{1,2}$, Dave Brown ${ }^{1}$, Andrew Parsons ${ }^{1}$, Gillian A. Whalley ${ }^{2}$, Nazimah Hamid ${ }^{1}$, Kevin Kantono ${ }^{1}$, Bruce \\ Donaldson $^{1}$, \& Elaine Rush ${ }^{1}$ \\ ${ }^{1}$ AUT Food Network, Auckland University of Technology, Auckland, New Zealand \\ ${ }^{2}$ Faculty of Social and Health Sciences, Unitec Institute of Technology, Auckland, New Zealand \\ Correspondence: Elaine Rush, AUT Food Network, Auckland University of Technology, PO Box 92006, \\ Wellesley St, Auckland, New Zealand. Tel: 0064-9-9219758. E-mail: elaine.rush@aut.ac.nz
}

Received: July 12, 2015 Accepted: August 9, 2015 Online Published: August 19, 2015

doi:10.5539/jfr.v4n5p64 URL: http://dx.doi.org/10.5539/jfr.v4n5p64

\begin{abstract}
Taste appeal, sustainable ingredients and valid health claims are challenges for successful marketing of healthier food products. This study was designed to compare the effects of branding, ingredients and nutrition information on consumer liking towards a prototype of the Nothing Else healthier snack bar with the top three brands of New Zealand snack bars, and another product with a good nutrient profiling score. Sixty-four consumers were recruited to evaluate the five snack bars. Participants initially blind-rated on visual analogue scales their liking scores in relation to colour, taste, flavour, texture and overall liking. Packaging for the products was then presented alongside each of the five products and participants rated their liking scores for a second time. Participants also ranked the five products from 1 to 5 for healthiness, taste, naturalness, and purchase intent if prices were the same. In both blind and informed tests, the Nothing Else bar was the least liked snack bar among all the tested samples. However, after the packaging for the products was presented, overall liking of the Nothing Else bar increased by $14 \%(p=0.023)$, while overall liking for the four commercial products were unchanged. While the most popular commercial bar was ranked the highest for taste and purchase intent, the Nothing Else bar was ranked the highest for the healthiness and naturalness. Our findings confirmed that the branding and health related nutrition information could improve consumer liking and brand perception particularly if backed by marketing.
\end{abstract}

Keywords: brand perception, healthier snacking, Nothing Else, sensory properties

\section{Introduction}

In response to the growing consumer demands for healthier foods (Siró, Kápolna, Kápolna, \& Lugasi, 2008), many food manufacturers have reformulated established brand products. However, taste appeal, sustainable ingredients and valid health claims are challenges for successful marketing of healthier food products. While taste is the most important factor for consumer perception in general (Fernqvist \& Ekelund, 2014), healthiness is suggested to be another factor which influences consumers' choice (Roininen, Lähteenmäki \& Tourila, 1999; Provencher, Polivy, \& Herman, 2009; Carillo, Varela, Salvador, \& Fiszman, 2011). Extrinsic product factors, such as region of origin of a wine can influence consumer perception (Mueller \& Szolnoki, 2010). Mueller and Szolnoki (2010) reported that labelling and branding have a strong impact on product liking. In recent years, nutrition information, and front-of-pack labelling particularly, have been introduced as ways to encourage healthier food choices (Steenhuis et al., 2010; van Herpen \& Trijp, 2011). However, consumers pay little attention to this information which limits its effectiveness (Bialkova \& van Trijp, 2010).

Snacking between main meals has become increasingly important in daily life (Savige, MacFarlane, Ball, Worsley, \& Crawford, 2007). However snacking behaviour has not been well researched or understood (Bilman, van Trijp \& Renes, 2010). Snack foods usually are categorized around the eating situations, rather than their health properties (Bilman et al., 2010). Although 'muesli-style' snack bars are regarded as being healthy, in a survey undertaken by the primary researcher of this study (data not published), most of the snack bars in New Zealand supermarket are high in sugar and fat, low in protein, fruits, nuts and dietary fibre, with many E numbered additives. They do not have nutrient profiling scores as defined by Food Standards Australia New Zealand (FSANZ) (2012) that allow them to make a health claim. In New Zealand, the score should be 4 or less 
but in the survey we found that scores ranged from 6 to 22 .

The Nothing Else, a brand created at Auckland University of Technology, New Zealand (Brown et al., 2015), was introduced in 2010 with the intent to promote sustainable consumption. Since 2013, the Nothing Else healthier snack bar has been developed, and the resultant almonds and dates bar was the third product of the Nothing Else brand. The Nothing Else bar uses eight perceived natural ingredients, is high in fibre and low in sodium according to FSANZ (2012), and has a low glycaemic index of 52 (data not published). An informal sensory trial showed that potential consumers found the taste, healthiness and natural ingredients as favourable features of the bar (Brown et al., 2015).

This study aimed to investigate the effects of branding, ingredients and nutrition information on sensory acceptability/liking of the Nothing Else snack bar, compared to top snack bars brands in New Zealand. The secondary aim was to investigate the relative importance of healthiness, taste, naturalness of foods to consumers. The main hypothesis was that branding, ingredients and nutrition information would influence consumer liking.

\section{Method}

\subsection{Experimental approach}

Sensory evaluation (Lawless \& Heymann, 2010) describes procedures in food manufacturing and technology to determine the acceptability and consumer responses towards the quality of new food products. Direct consumer testing is where sensory information is collected directly from individuals without formal training in sensory evaluation. The test enables manufacturers to predict likely market behaviour (Giacalone, Bredie, \& Frøst, 2012). In addition, consumer opinions can be incorporated as part of the refinement and optimal design of food products (Lawless \& Heymann, 2010). Consumers rate their liking for various attributes of a given food product on a defined scale (Schutz, 1999; Lawless \& Heymann, 2010). A scaling method with low inter-individual variability will allow more sensitive tests and thus a lower risk of missing a true difference (Lawless \& Heymann, 2010). Unstructured horizontal line scaling with only the endpoints marked with short line segments was adopted for the current study because the visual analogue scale allows consumers choice to be more continuous and therefore less limited.

\subsection{Participants}

Sixty-four participants (Table 1) were recruited for the present study. Participants were comprised of staff members and students from two tertiary education institutes in Auckland, New Zealand. The demographic of this population meant that about half the participants were of Asian origin (Table 1). Eligibility criteria required that participants were 18 years or older, consumed snack bars at least once a week, and had no known allergies to food ingredients including nuts, gluten, egg, and milk. The sample size to measure the degree of liking of consumers by the use of visual analogue scales (VAS) was determined from the usual requirement for fifty or more untrained persons (Lawless \& Heymann, 2010; Sensory analysis, 2014). The effective sample size, nevertheless, was based on what is seen during the course of the study (Cohen, 1988). Ethics approval for this study was provided by Auckland University of Technology Ethics Committee (Reference no. 13/184).

Table 1. Demographic characteristics of the 64 participants

\begin{tabular}{|c|c|c|c|}
\hline & Total & $\begin{array}{c}\text { Age } \\
20 \text { to } 29 \text { yrs }\end{array}$ & $\begin{aligned} & \text { Age } \\
& \geq 30 \mathrm{yrs} \\
&\end{aligned}$ \\
\hline \multicolumn{4}{|l|}{ Gender } \\
\hline Men & 23 & 13 & 10 \\
\hline Women & 41 & 28 & 13 \\
\hline \multicolumn{4}{|l|}{ Ethnicity } \\
\hline Asian & 38 & 31 & 7 \\
\hline Non-Asian & 26 & 10 & 16 \\
\hline
\end{tabular}




\subsection{Sample Preparation for Sensory Analysis}

The Nothing Else prototype bar was prepared in the food laboratory in School of Applied Science, AUT University. Four commercial products included the three top New Zealand brands of snack bars $(45 \%$ of the market share, Euromonitor International, 2012), and another product that was similar in nutrition profiling score to the Nothing Else bar (Table 2). All commercial products were purchased from local supermarkets in Auckland, New Zealand.

Snack bars were cut into a $2 \times 2 \mathrm{~cm}^{2}$ pieces and were presented to the consumers at room temperature $\left(20^{\circ} \mathrm{C}\right)$ on white, covered food grade plastic containers under white light. The samples were identified by individual three digit codes, which were randomized, and counter balanced to order of presentation using a Latin square design (Macfie, Bratchell, Greenhoff, \& Vallis, 1989) to reduce participant and researcher bias.

Table 2. Samples for consumer liking testing

\begin{tabular}{clcc}
\hline Code & Brand & Market share ${ }^{1}$, MAT $^{2}$ to (\%) & Nutrient profiling score $^{3}$ \\
\hline B1 & Brand 1 & 15.9 & 11 \\
B2 & Brand 2 & 15.9 & 12 \\
B3 & Brand 3 & 14.7 & 15 \\
B4 & Brand 4 & & 1 \\
NE & Nothing Else & & -1 \\
\hline
\end{tabular}

${ }^{1}$ Ranked in order of sales value in NZ in 2012 (Euromonitor International, 2012)

${ }^{2}$ MAT: moving annual total

${ }^{3}$ Derived from nutrient profiling model (FSANZ, 2012). A food with a score $>4$ is unable to make health claims.

\subsection{Experimental Protocol}

Participants were asked to attend test sessions at least two hours after breakfast in the morning. Each participant was seated at a table separated by partitions to ensure they did not interact or influence other participants. After reading the study information and asking any questions, participants were asked to sign the consent form before the testing started.

A three stage evaluation procedure was applied: a) sensory evaluation in a blind condition; b) sensory evaluation with the knowledge of branding, ingredients and nutrition information; c) ranking of the importance of healthiness, taste, and naturalness to consumers.

In the first stage blind condition, the Nothing Else prototype was presented twice to measure the reliability of participants. Each participant tasted six samples in a blind condition and evaluated his or her liking in relation to colour, taste, flavour, texture, and overall liking on five $100 \mathrm{~mm}$ unstructured line scales anchored at dislike extremely (left end) and like extremely (right end) (Figure 1). Participants were asked to rinse their mouth with water between tasting each sample.

In the informed condition, five samples were presented to participants together with the actual front and back pack labels showing the brand, the name of the bar, all the ingredients and nutrition information. For all products, the labels and nutrition panels were colour printed and presented in the same format. Each participant tasted the five samples and evaluated his or her liking in relation to colour, taste, flavour, texture, and overall liking again on five unstructured line scales. When participants completed this, they were additionally asked to rank the perceived healthiness, taste, and naturalness and purchase intent each from 1 to 5 , with 1 being the lowest and 5 being the highest ranking if prices were the same for the snack bars. Participants were also asked to state the importance of healthiness, taste and naturalness from 1 to 5 , with 1 being not important and 5 being very important.

Extremely Dislike

Extremely Like

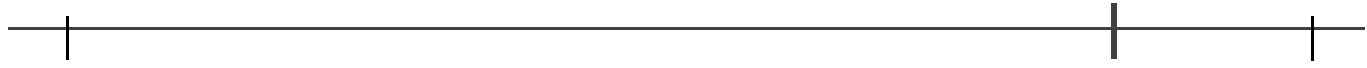

Figure 1. Line scaling for measuring consumer liking/disliking in relation to sensory attributes on a $100 \mathrm{~mm}$ visual analogue scale (VAS) 


\subsection{Data Analysis}

Distance data, to the nearest $\mathrm{mm}$, were measured with a digital calliper (Warrior, Canada) from the left hand anchor point. To compare the repeat measures of the Nothing Else bar, two tailed paired $t$-test was used. The mean value of the replicate tests for each attribute of the Nothing Else bar was used in the comparison with the four commercial bars. Separately for blind and informed tests means of hedonic liking on 5 sensory attributes (overall liking, colour, taste, flavour, and texture) were calculated and statistically tested using one-way analysis of variance (ANOVA) to determine if a statistical difference existed at $p<0.05$. Tukey's post-hoc test was then used to identify which specific means were significantly different. Friedman test was carried out for rank sum total (sum total of ranking each of all participants) data on perceived healthiness, taste, naturalness, and purchase intent. Multiple pairwise comparisons with the Bonferroni correction were carried out in order to identify statistical separation among the sum ranking total. The effects of age and ethnicity on liking were analysed using two-way ANOVA. The univariate analysis in this study was carried out using SPSS version 14.0.1, 2005 (SPSS Inc., Chicago, Ill.). Multivariate analysis in this study was carried out using XLSTAT version 2013.4.08 (Addinsoft, USA).

\section{Results}

When the Nothing Else bar was presented to the 64 participants as two of six randomised samples in a blind test, there was no meaningful difference between the mean values of liking for the 5 sensory attributes. For instance, there was only, on average, a $0.5 \mathrm{~mm}$ difference for a mean score of $34 \mathrm{~mm}$ out of $100 \mathrm{~mm}$ for overall liking (Table 3). However, across all 5 sensory attributes, the standard deviations of the paired differences were large (mean difference < 1.0, SD 15 to 21).

The Nothing Else bar had meaningfully lower scores compared with all four commercial snack bars across all 5 sensory attributes for both blind and informed tests with the 64 subjects (Table 3). The four commercial bars were rated by the participants in the same order of liking as the value of commercial sales (Table 2). The rating scores of Brand 1 were similar to that of Brand 2, but were meaningfully different to Brand 3 and Brand 4, across all 5 sensory attributes for both blind and informed tests (Table 3).

In the blind test, the Nothing Else bar was consistently and significantly $(p<0.0001)$ the least overall liked of all other bars. Brand 1 was overall liked more than all the other bars. Brand 2 was liked more than both of Brand 3 and Brand 4. There was however no difference in overall liking between Brand 3 and Brand 4. The Nothing Else bar was rated lower for taste than all other brands except for Brand 4.

Table 3. Sensory attribute ratings obtained from blind and informed consumer tests $(n=64)$, comparing the Nothing Else bar with four commercial products

\begin{tabular}{|c|c|c|c|c|c|c|}
\hline \multirow{2}{*}{$\begin{array}{l}\text { Product } \\
\text { Attribute }(\mathrm{mm})\end{array}$} & $\mathrm{NE}^{*}$ & B1 & B2 & B3 & B4 & \\
\hline & \multicolumn{5}{|c|}{ Mean (SE) } & $\$ p$ value \\
\hline \multicolumn{7}{|l|}{ Blind } \\
\hline Overall liking & $34.3(2.52)$ & $73.0^{\mathrm{a}}(2.07)$ & $62.1^{\mathrm{a}, \mathrm{b}}(2.56)$ & $52.2^{\mathrm{a}, \mathrm{b}, \mathrm{c}}(2.93)$ & $49.6^{\mathrm{a}, \mathrm{c}}(2.77)$ & $<0.0001$ \\
\hline Colour & $38.2(2.36)$ & $73.6^{\mathrm{a}}(1.86)$ & $63.1^{\mathrm{a}, \mathrm{b}}(2.47)$ & $46.3^{\mathrm{a}, \mathrm{b}, \mathrm{c}}(2.60)$ & $47.8^{\mathrm{a}, \mathrm{c}}(2.59)$ & $<0.0001$ \\
\hline Taste & $32.2(2.49)$ & $72.6^{\mathrm{a}}(2.09)$ & $61.7^{\mathrm{a}, \mathrm{b}}(2.80)$ & $52.8^{\mathrm{a}, \mathrm{b}, \mathrm{c}}(3.22)$ & $49.0^{\mathrm{a}, \mathrm{c}}(3.12)$ & $<0.0001$ \\
\hline Flavour & $33.6(2.78)$ & $73.3^{\mathrm{a}}(2.06)$ & $64.1^{\mathrm{a}, \mathrm{b}}(2.70)$ & $54.3^{\mathrm{a}, \mathrm{b}, \mathrm{c}}(3.10)$ & $49.8^{\mathrm{a}, \mathrm{c}}(3.13)$ & $<0.0001$ \\
\hline Texture & $33.8(2.62)$ & $70.8^{\mathrm{a}}(2.06)$ & $64.1^{\mathrm{a}, \mathrm{b}}(2.79)$ & $51.3^{\mathrm{a}, \mathrm{b}, \mathrm{c}}(2.99)$ & $50.0^{\mathrm{a}, \mathrm{c}}(3.32)$ & $<0.0001$ \\
\hline \multicolumn{7}{|l|}{ Informed } \\
\hline Overall liking & $39.0^{\dagger}(2.89)$ & $71.0^{\mathrm{a}}(2.25)$ & $60.0^{\mathrm{a}, \mathrm{b}}(2.62)$ & $52.5^{\mathrm{a}, \mathrm{b}, \mathrm{c}}(2.79)$ & $52.0^{\mathrm{a}, \mathrm{c}}(2.97)$ & $<0.0001$ \\
\hline Colour & $38.9(3.01)$ & $71.1^{\mathrm{a}}(2.23)$ & $60.1^{\mathrm{a}, \mathrm{b}}(2.62)$ & $52.5^{\mathrm{a}, \mathrm{b}, \mathrm{c}}(2.79)$ & $48.5^{\mathrm{a}, \mathrm{c}}(2.66)$ & $<0.0001$ \\
\hline Taste & $36.8^{\dagger}(2.87)$ & $70.9^{\mathrm{a}}(2.25)$ & $59.6^{\mathrm{a}, \mathrm{b}}(2.80)$ & $52.8^{\mathrm{a}, \mathrm{b}, \mathrm{c}}(2.88)$ & $49.5^{\mathrm{a}, \mathrm{c}}(3.12)$ & $<0.0001$ \\
\hline Flavour & $37.0(2.93)$ & $72.5^{\mathrm{a}}(2.00)$ & $60.2^{\mathrm{a}, \mathrm{b}}(2.74)$ & $53.4^{\mathrm{a}, \mathrm{b}, \mathrm{c}}(2.83)$ & $50.3^{\mathrm{a}, \mathrm{c}}(3.17)$ & $<0.0001$ \\
\hline Texture & $35.3(2.85)$ & $71.2^{\mathrm{a}}(2.18)$ & $61.1^{\mathrm{a}, \mathrm{b}}(2.73)$ & $50.4^{\mathrm{a}, \mathrm{b}, \mathrm{c}}(3.01)$ & $48.3^{\mathrm{a}, \mathrm{c}}(3.36)$ & $<0.0001$ \\
\hline
\end{tabular}

NE, Nothing Else bar; B1 to B4, four commercial products; *In blind test, the NE values are the mean values of the replicate tests; $\$$ ANOVA.

Within the same row, ${ }^{\mathrm{a}}$ Mean value was significantly different to NE $(p<0.05)$; ${ }^{\mathrm{b}}$ Mean value was significantly different to $\mathrm{B} 1(p<0.05)$; ${ }^{\mathrm{C}}$ Mean value was significantly different to $\mathrm{B} 2(p<0.05)$.

${ }^{\dagger}$ Different to blind test ( $p=0.023,0.042$ for overall liking, taste, respectively). 
After the packaging and branding for the bars were presented alongside the samples for testing in the informed test, the overall liking of the Nothing Else bar remained the lowest but increased by 5 percentage points from 34 to 39 , showing a $14 \%$ improvement $(p=0.023)$ compared to the blind test. The taste score of the Nothing Else bar increased by 4.6 percentage points from 32.2 to $36.8 \%(p=0.042)$. However, overall liking and taste scores for all the other bars did not change with packaging and brand knowledge.

When participants were asked to rank the five bars on healthiness, taste, naturalness, and purchase intent provided that prices were the same for all brands, Brand 1 was ranked the highest for both taste and purchase intent, while the Nothing Else bar was ranked the lowest (Table 4). Conversely the Nothing Else bar was ranked the highest for both naturalness and healthiness while Brand 1 was rated the lowest. The healthiness and naturalness rank sum total of the Nothing Else and Brand 4 were similar, and were significantly higher than those of the top three brands (B1, B2 and B3). When taste and purchase intent scores were compared, the rank sum total for Brand 1 was much higher than that for all other bars which were not different to each other.

Of the perceptions of importance of healthiness, taste and naturalness to consumers, taste was considered the most important, followed by healthiness, and then naturalness. However, there was no meaningful difference in importance of these three perceptions when the mean rankings were compared (3.9, 3.6 and 3.3, respectively).

Table 4. Rank sum total of healthiness, taste, naturalness, and purchase intent for five products from informed test $(n=64)$

\begin{tabular}{|c|c|c|c|c|c|}
\hline $\begin{array}{lr} & \text { Product } \\
\text { Perception } & \end{array}$ & $\mathrm{NE}$ & B1 & B2 & B3 & B4 \\
\hline Taste & 161 & $251^{\mathrm{a}}$ & 197 & 188 & 168 \\
\hline Healthiness & 242 & $136^{\mathrm{a}}$ & $142^{\mathrm{a}}$ & $191^{\mathrm{a}}$ & 234 \\
\hline Naturalness & 253 & $137^{\mathrm{a}}$ & $146^{\mathrm{a}}$ & $185^{\mathrm{a}}$ & 208 \\
\hline Purchase intent & 166 & $222^{\mathrm{a}}$ & 181 & 182 & 178 \\
\hline
\end{tabular}

NE, Nothing Else; B1 to B4, four commercial products. Each perception was ranked from 1 (lowest) to 5 (highest). Within the same row, ${ }^{\mathrm{a}}$ Rank sum total was significantly different to others at $p<0.05$ (Friedman test post hoc).

There were no meaningful differences based on age, gender and ethnicity of participants on either the blind or the informed test. However, when the tests of between-subjects effects were performed, differences were found (Table 5). The informed overall liking scores increased significantly with the older age group $(p=0.019)$, the male participants $(p=0.014)$, and non-Asian ethnic group $(p=0.011)$, in comparison with blind overall liking scores.

Of the perceptions of importance of healthiness, taste and naturalness to consumers, taste was considered more important than healthiness and naturalness for all age, gender, and ethnic groups.

Table 5. The effects of impact factors (age, gender and ethnicity) with 64 participants on overall liking scores of the Nothing Else bar in blind and informed tests

\begin{tabular}{lccc}
\hline Characteristics & \multicolumn{2}{c}{ Overall liking $(\mathrm{mm})$} & $p$ value \\
& Mean (SE) & \\
\cline { 2 - 4 } & $35.1(3.18)$ & Informed & 0.524 \\
\hline 20 to 29 yrs & $33.7(4.25)$ & $39.6(3.64)$ & 0.019 \\
$\geq 30$ yrs & $30.3(4.11)$ & $37.3(4.82)$ & 0.014 \\
Men & $37.0(3.14)$ & $39.9(3.64)$ & 0.305 \\
Women & $31.9(3.26)$ & $33.9(3.65)$ & 0.127 \\
Asian & $38.5(3.94)$ & $46.4(4.41)$ & 0.011 \\
Non-Asian & &
\end{tabular}




\section{Discussion}

The Nothing Else snack prototype was least overall liked in comparison to the four commercial snack products, which was not surprising in view of its nutritional profile that was markedly different from the other bars, particularly in fibre content. Also the prototype was developed with low sugar and low fat contents to achieve a good nutrient profiling score (FSANZ, 2012). Both sugar and fat are perceived as mouthfeel enhancers and flavour carriers and were high in the top three commercial bars. Brand 1 had the highest fat content $(31.6 \mathrm{~g}$ per $100 \mathrm{~g}$ ) compared to all other samples and Brand 3 had the highest sugar content ( $35.8 \mathrm{~g}$ per $100 \mathrm{~g})$. The Nothing Else bar had less fat content (17g per 100g) and the least sugar content $(20 \mathrm{~g}$ per $100 \mathrm{~g}$, Appendix). Sugar and fat are known to influence consumers' acceptance and liking of a food product. Drewnoski (1989) demonstrated that consumers have developed sensory preferences for fat and sugar compared to other macronutrients both in their adolescence and adult life. Studies on ice cream also revealed that higher sugar and fat contents were correlated with consumers' acceptance (Guinard, Zoumas-Morse, Panyam, \& Kilara, 1996; Guinard et al., 1997).

Branding and packaging of a food has an influential effect on consumer perception and has become an increasingly important factor in the food marketing system. Consumer trust and loyalty enhance consumer perceived value of a food product (Kapferer, 2004). However, which part of brand generates consumers' beliefs is not fully clear (Fernqvist \& Ekelund, 2014). While healthiness is important, the taste of a food still remains a higher priority for consumers: consumers purchase intent is mainly influenced by taste and price. For health conscious consumers, nutrition and health claims have positive effects on the hedonic rating (Villegas, Carbonell \& Costtell, 2008; Carillo, Varela, \& Fiszman, 2012). In general, older consumers are more concerned about health than younger consumers (Roininen et al., 1999). Azzurra and Paola (2009) reported that mature people aged $\geq 35$ years with higher level of education were particularly interested in health-related features of nutrition and foods. However in some studies, no association between health interest and consciousness and the hedonic ratings has been demonstrated (Fernqvist \& Ekelund, 2014). Although interindividual variation in responses was high, there is some evidence that age and ethnicity of participants influenced liking in this study. Non-Asian and older participants liked the Nothing Else prototype more than Asian and younger participants.

The findings of this study illustrate the relative effects of branding and nutrition information on informed liking of the Nothing Else snack prototype. In the present study, the presence of branding did not improve the ratings of consumer liking for the four commercial snack products. There is insufficient evidence that branding of the commercial products had positive effects on liking where the overt listing, front-of pack, of all the ingredients on and health related information were associated with improved overall liking of the Nothing Else bar. The Nothing Else bar uses eight ingredients that are perceived as natural. Furthermore, it presented the general health parameters such as a low glycaemic index, a good fibre content, and a low sodium content (Brown et al., 2015).

The main limitation of the current relatively small study was that the design of this analysis was unbalanced by age and ethnic groups. Furthermore, the participants were a convenience sample and not representative of the population. Two thirds of the participants were relatively young, aged 20 to 29 years. Also almost two thirds of the study population were Asian. A comparison between different age groups found that the older age group ( $\geq$ 30 years) scored the sensory attributes of the Nothing Else bar higher and the most popular brand lower than that of the younger age group (20 to 29 years- data not shown). In addition, 'muesli-style' snack bars are not common snacks for Asian people who tended to rate the bars lower than Non-Asian people. We propose that this might be due to food neophobia (unfamiliarity to food) of muesli and oat-based products among the Asian population. A study undertaken by Chung et al. (2012) demonstrated the differences in liking for Korean-style salad dressings and beverages between USA and Korean consumers living in North American in relation to context and cultural factors. They concluded that non-Korean consumers showed food neophobia contributing to the disliking of Korean style salad dressing. Furthermore, the Nothing Else brand was new to most participants but familiarity of participants with the other established brands could have affected the scores of the informed test. Therefore, sensory trial participants should be purposively selected in a more rigorous way. Future work is required to understand the magnitude of the effects of branding in the target group of consumers.

The hypothesis that branding and health information would improve consumer liking was confirmed in this study. Although the mean liking score of each sensory attribute of the Nothing Else bar was different than that of the four commercial products, there was a meaningful improvement in consumer overall liking of the Nothing Else snack prototype when branding and nutrition information were associated with the product. Future trials need to look at intra-individual variability in response to the effect of repeated exposure to a food as a one-off taste trial does not predict how consumers may adapt and like a product more with repeated exposure (Stein, Nagai, Nakagawab, \& Beauchamp, 2003), as shown in our sales trial (Brown et al., 2015). 


\section{Conclusion}

This study has produced evidence that a healthier snack bar with clear front-of-pack labelling listing all the ingredients 'Nothing Else' was overall liked more than in the blind condition when the packaging was shown to consumers. This was not the case for other four commercial snack products. Our findings confirmed that the branding and health related nutrition information could improve consumer liking and brand perception particularly if backed by marketing.

\section{Acknowledgments}

The authors wish to sincerely thank Peter Tan, the director of AB Foods Ltd., Auckland, who provided funding and facilities for the development of the Nothing Else snack bar. Thanks to Dr Owen Young, Professor of Food Science at AUT, for valuable advice. We also wish to thank the laboratory staff in the School of Applied Science, AUT University for their technical assistance and support.

\section{References}

Azzurra, A., \& Paola, P. (2009). Consumers' behaviours and attitudes toward healthy food products: The case of Organic and Functional foods. Paper prepared for presentation at the $113^{\text {th }}$ EAAE Seminar "A resilient European food industry and food chain in a challenging world", Crete, Greece. Retrieved from http://ageconsearch.umn.edu/bitstream/57661/2/Annunziata.pdf

Bialkova, S., \& van Trijp, H. (2010). What determines consumer attention to nutrition labels? Food Quality and Preference, 21(8), 1042-1051. http://dx.doi.org/10.1016/j.foodqual.2010.07.001

Bilman, E. M., van Trijp, J. C., \& Renes, R. J. (2010). Consumer perceptions of satiety-related snack food decision making. Appetite, 55(3), 639-647. http://dx.doi.org/10.1016/j.appet.2010.09.020

Brown, D., Donaldson, B., Parsons, A., Macrae, D., Kelleher, J., Yan, M., \& Rush, E. (2015). The Nothing Else: A case study. Food and Nutrition Sciences, 6, 332-338. http://dx.doi.org/10.2436/fns.2015.6033

Carillo, E., Varela, P., Salvador, A., \& Fiszman, S. (2011). Main factors underling consumers' perception of enriched and reduced-calorie biscuits in tasting and non-tasting tests. Journal of Sensory Studies, 26, 85-95.

Carillo, E., Varela, P., \& Fiszman, S. (2012). Effects of food package information and sensory characteristics on the perception of healthiness and the acceptability of enriched biscuits. Food Research International, 48, 209-216. http://dx.doi.org/10.1016/j.foodres.2012.03.016

Chung, L., Chung, S. J., Kim, J. Y. Kim, K. O., O’Mahony, M., Vickers, Z., Cha, S., Ishii, R., Baures, K., \& Kim, H-R. (2012). Comparing the liking for Korean style salad dressings and beverages between US and Korean consumers: Effects of sensory and non-sensory factors. Food Quality and Preference, 26, 105-118. http://dx.doi.org/10.1016/ j.foodqual.2012.03.011

Cohen, J. (1988). Statistical power analysis for behavioural sciences (2nd ed.). Hillsdale, NJ: Lawrence Erlbaum Associates.

Drewnowski, A. (1989). Sensory preferences for fat and sugar in adolescence and adult life. Annals New York Academiy of Siemces, 561, 243-250. http://dx.doi: 10.1111/j.1749-6632.1989. tb20986.x

Euromonitor International. (2012). Snack bars in New Zealand. Annual report.

Fernqvist, F., \& Ekelund, L. (2014). Credence and the effect on consumer liking of food - A review. Food Quality and Preference, 32, 340-353. http://dx.doi.org/10.1016/j.foodqual.2013.10.005

Food Standards Australia New Zealand. (2012). Nutrition, health and related claims. Review report. Retrieved from http://www.foodstandards.govt.nz/code/proposals/pages/proposalp293nutritionhealthandrelatedclaims/ default.aspx

Giacalone, D., Bredie, W. I. P., \& Frøst, M. B. (2012). "All-in-one test” (Ai1): a rapid and easily applicable approach to consumer product testing. Food Quality and Preference, 27, 108-119. http://dx.doi.org/10.1016/jfoodqual.2012.09011

Guinard, J. X., Zoumas-Morse, C., Panyam, D., \& Kilara, A. (1996). Effect of sugar and fat on the acceptability of vanilla ice cream. Journal of Dairy Science, 79(11), 1922-1927. http://dx.doi.org/10.3168/jds.S0022-0302(96)76561-X

Guinard, J. X., Zoumas-Morse, C., Mori, L., Uatoni, B., Panyam, D., \& Kilara, A. (1997). Sugar and fat effects on sensory properties of ice cream. Journal of Food Science, 62(5), 1087-1094. http://dx.doi.org/10.1111/j.1365-2621.1997.tb15044.x 
Kapferer, J. N. (2004). The new strategic brand management (3rd ed.). London: Kogan Page.

Lawless, H. T., \& Heymann, H. (2010). Sensory evaluation of food: principles and practices. New York, NY: Springer.

Macfie, H. J., Bratchell, N., Greenhoff, K., \& Vallis, L. V. (1989). Designs to balance the effect of order of presentation and first-order carry-over effects in hall tests. Journal of Sensory Studies, 4, 129-148. http://dx.doi.org/10.1111/j.1745-459X.1989.tb00463.x

Mueller, S., \& Szolnoki, G. (2010). The relative influence of packaging, labelling, branding and sensory attributes on liking and purchase intent: Consumers differ in their responsiveness. Food Quality and Preference, 21(7), 774-783. http://dx.doi.org/10.1016/j.foodqual.2010.07.011

Provencher, V., Polivy, J., \& Herman, C. P. (2009). Perceived healthiness of food. If it's healthy, you can eat more! Appetite, 52, 340-344. http://dx.doi.org/10.1016/j.appet.2008.11.005

Roininen, K., Lähteenmäki, L., \& Tourila, H. (1999). Quantification of consumer attitudes to health and hedonic characteristics of food. Appetite, 33, 71-88.

Savige, G., MacFarlane, A., Ball, K., Worsley, A., \& Crawford, D. (2007). Snacking behaviours of adolescent and their association with skipping meals. International Journal of Behavioural Nutrition and Physical Activity, 4, 36-44. http://dx.doi.org/10.1186/1479-5868-4-36

Schutz, H. G. (1999). Consumer data-sense and nonsense. Food Quality and Preference, 10, 245-251.

Sensory analysis (2014). In Wikipedia, the free encyclopedia. Retrieved January, 12, 2014, http://en.wikipedia.org/wiki/Sensory_analysis

Siró, I., kápolna, E., Kápolna, B., \& Lugasi, A. (2008). Functional food. Product development, marketing and consumer acceptance - A review. Appetite, 51(3), 456-467. http://dx.doi: 10.1016/j.appet.2008.05.060

Steenhuis, I. H., Kroeze, W., Vyth, E. L., Valk, S., Verbauwen, R., \& Seidell, J. C. (2010). The effects of using a nutrition logo on consumption and product evaluation of a sweet pastry. Appetite, 55(3), 707-709. http://dx.doi.org/10.1016/j.appet.2010.07.013

Stein, L. J., Nagai, H., Nakagawab, M., \& Beauchamp, G. K. (2003). Effects of repeated exposure and health-related information on hedonic evaluation and acceptance of a bitter beverage. Appetite, 40, 119-129. http://dx.doi.org/10.1016/S0195-6663(02)00173-3

van Herpen, E., \& Trijp, H. C. (2011). Front-of-pack nutrition labels. Their effect on attention and choices when consumers have varying goals and time constraints. Appetite, 57(1), 148-160. http://dx.doi.org/10.1016/j.appet.2011.04.011

Villegas, B., Carbonell, I., \& Costell, E. (2008). Effects of product information and consumer attitudes on responses to milk and soybean vanilla beverage. Journal of the Science of Food and Agriculture, 88, 2426-2434. http://dx.doi.org/10.1002/jsfa.3347

\section{Appendix}

Table A-1. Nutritional information panel of the test products per $100 \mathrm{~g}$

\begin{tabular}{lccccccc}
\hline Food & $\begin{array}{c}\text { Energy } \\
(\mathrm{kJ})\end{array}$ & $\begin{array}{c}\text { Protein } \\
(\mathrm{g})\end{array}$ & $\begin{array}{c}\text { Fat total } \\
(\mathrm{g})\end{array}$ & $\begin{array}{c}\text { Saturated } \\
\text { fat }(\mathrm{g})\end{array}$ & $\begin{array}{c}\text { CHO } \\
(\mathrm{g})\end{array}$ & $\begin{array}{c}\text { Sugar } \\
(\mathrm{g})\end{array}$ & $\begin{array}{c}\text { Fibre } \\
(\mathrm{g})\end{array}$ \\
\hline Nothing Else* & 1544 & 11.6 & 17.1 & 2.1 & 44.9 & 20.3 & 8.2 \\
Brand 1 & 2160 & 14.2 & 31.6 & 6.7 & 40.2 & 23.8 & 5.5 \\
Brand 2 & 1880 & 10.3 & 21.3 & 9.0 & 55.7 & 24.4 & 5.0 \\
Brand 3 & 1610 & 6.5 & 14.1 & 7.4 & 60.1 & 35.8 & 4.8 \\
Brand 4 & 1430 & 8.9 & 1.3 & 0.3 & 68 & 21.4 & 9.0 \\
\hline
\end{tabular}

* Derived from food composition tables using FoodWorks version 7 (Xyris Pty Ltd., Australia). 


\section{Copyrights}

Copyright for this article is retained by the author(s), with first publication rights granted to the journal.

This is an open-access article distributed under the terms and conditions of the Creative Commons Attribution license (http://creativecommons.org/licenses/by/3.0/). 